\title{
Comprehensive biomechanical analysis of three reconstruction techniques following total sacrectomy: an in vitro human cadaveric model
}

\author{
Mohamed Macki, MD, MPH, ${ }^{1}$ Rafael De la Garza-Ramos, MD, ${ }^{2}$ Ashley A. Murgatroyd, BS, ${ }^{3}$ \\ Kenneth P. Mullinix, BA, ${ }^{3}$ Xiaolei Sun, MD, ${ }^{3}$ Bryan W. Cunningham, PhD, ${ }^{3}$ \\ Brandon A. McCutcheon, MD, MPP, ${ }^{4}$ Mohamad Bydon, MD, ${ }^{4}$ and Ziya L. Gokaslan, MD ${ }^{5}$
}

\begin{abstract}
'Department of Neurosurgery, Henry Ford Hospital, Detroit, Michigan; '2Department of Neurosurgery, Johns Hopkins University School of Medicine, Baltimore; ${ }^{3}$ Orthopaedic Spinal Research Institute, St. Joseph Medical Center, University of Maryland, Towson, Maryland; " ${ }^{\text {Department }}$ of Neurosurgery, Mayo Clinic, Rochester, Minnesota; and ${ }^{5}$ Department of Neurosurgery, Warren Alpert Medical School of Brown University, Providence, Rhode Island
\end{abstract}

OBJECTIVE Aggressive sacral tumors often require en bloc resection and lumbopelvic reconstruction. Instrumentation failure and pseudarthrosis remain a clinical concern to be addressed. The objective in this study was to compare the biomechanical stability of 3 distinct techniques for sacral reconstruction in vitro.

METHODS In a human cadaveric model study, 8 intact human lumbopelvic specimens (L2-pelvis) were tested for flexion-extension range of motion (ROM), lateral bending, and axial rotation with a custom-designed 6-df spine simulator as well as axial compression stiffness with the MTS 858 Bionix Test System. Biomechanical testing followed this sequence: 1) intact spine; 2) sacrectomy (no testing); 3) Model 1 (L3-5 transpedicular instrumentation plus spinal rods anchored to iliac screws); 4) Model 2 (addition of transiliac rod); and 5) Model 3 (removal of transiliac rod; addition of 2 spinal rods and 2 S-2 screws). Range of motion was measured at L4-5, L5-S1/cross-link, L5-right ilium, and L5-left ilium.

RESULTS Flexion-extension ROM of the intact specimen at $L 4-5\left(6.34^{\circ} \pm 2.57^{\circ}\right)$ was significantly greater than in Model $1\left(1.54^{\circ} \pm 0.94^{\circ}\right)$, Model $2\left(1.51^{\circ} \pm 1.01^{\circ}\right)$, and Model $3\left(0.72^{\circ} \pm 0.62^{\circ}\right)(p<0.001)$. Flexion-extension at both the L5right ilium $\left(2.95^{\circ} \pm 1.27^{\circ}\right)$ and the L5-left ilium $\left(2.87^{\circ} \pm 1.40^{\circ}\right)$ for Model 3 was significantly less than the other 3 cohorts at the same level ( $p=0.005$ and $p=0.012$, respectively). Compared with the intact condition, all 3 reconstruction groups statistically significantly decreased lateral bending ROM at all measured points. Axial rotation ROM at L4-5 for Model $1\left(2.01^{\circ} \pm 1.39^{\circ}\right)$, Model $2\left(2.00^{\circ} \pm 1.52^{\circ}\right)$, and Model $3\left(1.15^{\circ} \pm 0.80^{\circ}\right)$ was significantly lower than the intact condition $\left(5.02^{\circ} \pm 2.90^{\circ}\right)(p<0.001)$. Moreover, axial rotation for the intact condition and Model 3 at L5-right ilium $\left(2.64^{\circ} \pm 1.36^{\circ}\right.$ and $2.93^{\circ} \pm 1.68^{\circ}$, respectively) and L5-left ilium $\left(2.58^{\circ} \pm 1.43^{\circ}\right.$ and $2.93^{\circ} \pm 1.71^{\circ}$, respectively) was significantly lower than for Model 1 and Model 2 at L5-right ilium (5.14 $\pm 2.48^{\circ}$ and $4.95^{\circ} \pm 2.45^{\circ}$, respectively) $(p=0.036)$ and L5-left ilium $\left(5.19^{\circ} \pm 2.34^{\circ}\right.$ and $\left.4.99^{\circ} \pm 2.31^{\circ}\right)(p=0.022)$. Last, results of the axial compression testing at all measured points were not statistically different among reconstructions.

CONCLUSIONS The addition of a transverse bar in Model 2 offered no biomechanical advantage. Although the implementation of 4 iliac screws and 4 rods conferred a definitive kinematic advantage in Model 3, that model was associated with significantly restricted lumbopelvic ROM.

https://thejns.org/doi/abs/10.3171/2017.2.SPINE161128

KEY WORDS biomechanics; Galveston L-rod; lumbopelvic; sacrectomy; sacrum; sacral reconstruction

$\mathrm{S}$ ACRAL neoplasms with an aggressive nature or diffuse infiltration may require en bloc resection to achieve the longest disease-free survival. ${ }^{16}$ En bloc resections may require a complete removal of the sacrum, or total sacrectomy, which not only disrupts the continuity between the lumbar spine and pelvis but also destabilizes the biomechanical integrity of the spinal column. In a technical note in 1997, the first total sacrectomy reconstruction technique performed using a Galveston L-rod was described. ${ }^{7}$ The instrumentation technique was adopted from Allen

ABBREVIATIONS BMD = bone mineral density; EZ = elastic zone; LED = light-emitting diode; $M G R=$ modified Galveston reconstruction; NZ = neutral zone; ROM = range of motion; SIJ = sacroiliac joint; TFR = triangular frame reconstruction.

SUBMITTED October 1, 2016. ACCEPTED February 9, 2017.

INCLUDE WHEN CITING Published online August 4, 2017; DOI: 10.3171/2017.2.SPINE161128. 
and Ferguson, who used the Galveston L-rod to correct scoliotic deformities. ${ }^{1}$ In the technical note, it was demonstrated that following a total sacrectomy, a pedicular, segmental fixation of the lumbar spine can communicate with the ilia together with a Galveston L-rod. This bilateral liaison between the lumbar spine and the pelvis is completely independent of any sacral fixation points.

As lumbopelvic fixation techniques and theories continue to develop, further understanding in terms of their comparative biomechanical properties is necessary. Although the goal of the reconstruction techniques is to achieve optimal biomechanical spinopelvic stability and promote a successful spinal arthrodesis, clinical and radiographic evidence has indicated that instrumentation failure and loosening remains a clinical concern. ${ }^{6,17,18}$

Using a human cadaveric model, the purpose of this in vitro investigation was to 1) compare the multidirectional biomechanical properties at the lumbosacral and lumbopelvic junctions of 3 different reconstruction techniques following total sacrectomy, and 2) quantify the axial and anteroposterior shear translations of the L-5 vertebral body relative to the pelvis under direct axial compressive loading.

\section{Methods}

\section{Specimen Preparation}

A total of 8 fresh-frozen human lumbopelvic specimens (L2-pelvis) were harvested en bloc and stored at $-20^{\circ} \mathrm{C}$ in the biomechanics laboratory. Prior to biomechanical analysis, standard anteroposterior fluoroscopic images were obtained to exclude specimens demonstrating intervertebral disc or osseous pathology. Bone mineral density ([BMD], g/ $/ \mathrm{cm}^{3}$ ) scans were conducted using a Lunar Prodigy Scanner 8743 (GE Medical Systems) to calculate the BMD within the lower lumbar levels (L2-5). Consistent with established guidelines, normal BMD is designated by a T-score $>-1 \mathrm{~g} / \mathrm{cm}^{3}$; for osteopenia BMD is a T-score between $-1 \mathrm{~g} / \mathrm{cm}^{3}$ and $-2.5 \mathrm{~g} / \mathrm{cm}^{3}$; and for osteoporosis BMD is a T-score $<-2.5 \mathrm{~g} / \mathrm{cm}^{3} .{ }^{8}$ In preparation for biomechanical testing, the L-2 vertebral body was secured in a rectangular tubing foundation by using 4 , four-point compression screws. The inferior half of the pelvic girdle was then positioned in a large rectangular configuration container and transfixed using six to eight 6-mm-diameter Steinmann pins in the coronal and sagittal planes. Six Plexiglas lightemitting diode (LED) motion-detection markers were placed in the following locations: 1) L-4 and L-5 vertebral bodies ( $(\mathrm{n}=2) ; 2)$ right sacral ala $(\mathrm{n}=1) ; 3)$ right and left iliac wings $(n=2)$, and an additional marker was placed on the container base $(n=1)$. The markers were equipped with 3 noncollinear LEDs designed for detection by an optoelectronic motion measurement system (OptoTrak 3020 System). Following reconstruction, the right sacral ala LED marker was secured to the posterior instrumentation construct via attachment to the transverse connector; this marker measured the strength of the instrumentation connecting the spine to the pelvis. This marker therefore reflects the strength of the closed pelvic ring: sacrum plus sacroiliac ligament (substituted by L5-ilium instrumentation), ilium, and pubis.
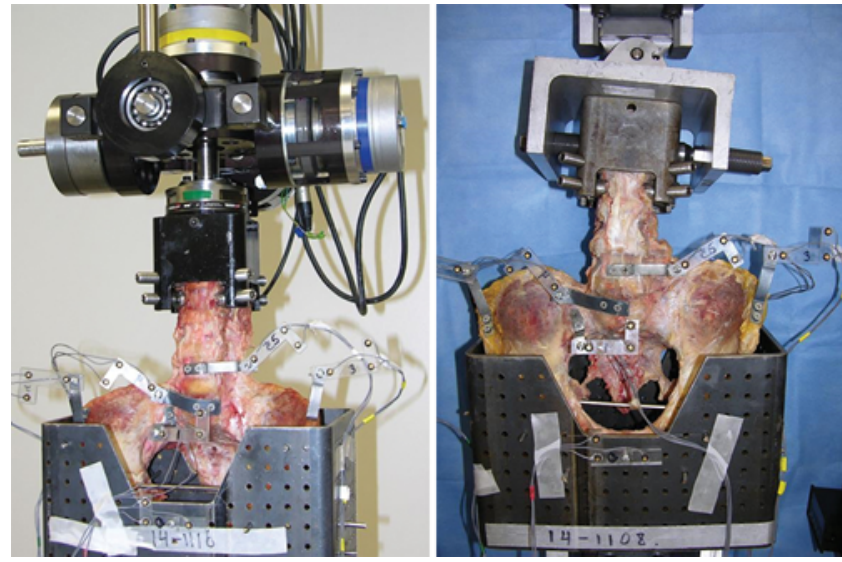

FIG. 1. Representative anterior views of 2 intact lumbopelvic specimens undergoing nondestructive multidirectional flexibility testing using a 6-df spine simulator (left); and axial compression testing using an MTS 858 Bionix Test System (right). Note that for both testing conditions, the compression screws of the superior fixation container were tightened directly against the rods at the L-2 vertebral level to ensure that load application was directed through the instrumentation and not the uninstrumented proximal adjacent levels. Figure is available in color online only.

\section{Biomechanical Testing}

The 3D multidirectional flexibility testing was performed using a custom-designed 6-df spine simulator (Fig. 1 left). The 3D peak range of segmental motions in the lower lumbar (L4-5), lumbosacral (L5-S1), and lumbopelvic (L5-left or L5-right iliac wings) regions was quantified in Euler angles (degrees rotation) by using an OptoTrak 3020 Motion Analysis System (Northern Digital, Inc.) interfaced with a Dell Dimension XPS T500 personal computer. All 8 lumbopelvic specimens were nondestructively tested under 6 sequential loading conditions, including flexion-extension ( \pm X-axis rotation, $\pm 12.5 \mathrm{Nm}$ ), lateral bending ( \pm z-axis rotation, $\pm 12.5 \mathrm{Nm}$ ), and axial rotation ( $\pm \mathrm{y}$-axis rotation, $\pm 12.5 \mathrm{Nm}$ ), using an unconstrained, pure-moment load at a rate of $3 \%$ second. Each rotational test was repeated for 3 loading and unloading cycles, with data from the third cycle used for computational analysis.

\section{Axial Compression Testing}

Using an MTS 858 Bionix Test System, axial compression testing was then performed from 0 to $-500 \mathrm{~N}$ at a constant load/unload rate of $50 \mathrm{~N} / \mathrm{second}$ and repeated for 3 loading and unloading cycles, with data from the third cycle used for computational analysis (Fig. 1 right). Testing was performed for the intact spine and 3 subsequent sacrectomy reconstruction procedures. Specimens were copiously moistened using $0.9 \%$ sodium chloride (normal saline) irrigation solution throughout the testing procedures.

\section{Specimen Destabilization and Reconstruction Procedures}

All 8 intact lumbopelvic specimens were biomechanically tested under the intact condition prior to undergoing instrumentation. Each specimen was then instrumented with transpedicular titanium screw-rod instrumentation (Expedium System; DePuy Synthes Spine, Inc.) extending from L-3 to L-5 by using 7-mm-diameter $\times 45-\mathrm{mm}$ - 
length screws and standard technique for pedicle screw placement. The posterior regions of the iliac wings, sacral cortex, and sacroiliac joint (SIJ) margins were then carefully cleared of residual musculature such that the first and second sacral foramen and SIJs were easily identified. A total of 4 tunnels were then prepared in the iliac wings ( 2 per side) to be used for iliac screw purchase following sacrectomy. The first set of bilateral tunnels originated just lateral to the second sacral foramen and were directed anterolaterally between the iliac cortical tables just superior to the sciatic notch, to a depth of $100 \mathrm{~mm}$ from the posterior margin. The second set of tunnels originated lateral to the first sacral foramen at the posterior superior iliac spine, and were directed anterolaterally and inferiorly between the iliac cortical tables. The central region of the ilium as viewed from the sagittal plane is thin, so every attempt was made to obtain screw purchase within the dense, boney structure superior to the acetabulum. Screw tunnels were prepared using a Lenke pedicle probe in the appropriate trajectory, and did not cross paths.

Following pedicle screw instrumentation of the lumbar spine and bilateral iliac screw-hole preparation, the sacrectomy procedure was performed. With the pelvis firmly secured to the 6-df platform, osteotomes were inserted and directed through the SIJs from the posterior to anterior pathway. The L5-S1 intervertebral disc was sectioned from the anterior direction and included transection of the entire intervertebral disc and spinal cord. Final transection of the bilateral articular facets at L5-S1 was performed from the posterior direction by using an osteotome, and the sacrum was removed en bloc from L-5 and the iliac wings.

\section{Reconstruction Treatment Groups Model 1}

Following sacrectomy, the superior iliac screw tunnels were tapped, followed by implantation of $8-\mathrm{mm} \times$ $80-\mathrm{mm}$ screws, such that the polyaxial screw heads were firmly embedded into the posterior iliac cortex. Bilateral rods $(5.5 \mathrm{~mm}$, titanium) were then contoured as needed, implanted extending from L-3, L-4, and L-5, and firmly attached to the bilateral iliac screws according to the manufacturer's guidelines for screw-tightening torques. The rods extended superior to L-3, which permitted the compression screws of the superior fixation container to be tightened directly against the rods. This ensured that the load application was directed through the instrumentation and not the proximal uninstrumented level. A crosslink was then implanted between the rods at L-5 and the iliac screws, and was securely tightened according to the manufacturer's guidelines. The LED OptoTrak marker originally attached to S-1 was reattached to the cross-link. This reconstruction method (Model 1, Fig. 2) was biomechanically evaluated using the loads previously applied to the intact spine condition.

\section{Model 2}

Following biomechanical testing of Model 1, a transverse titanium iliac bar (5.5-mm diameter) was implanted through and spanning the posterior iliac wings. Two holes (1 per ilium) $5 \mathrm{~mm}$ in diameter were placed through the posterior iliac wings and located superior to the previously

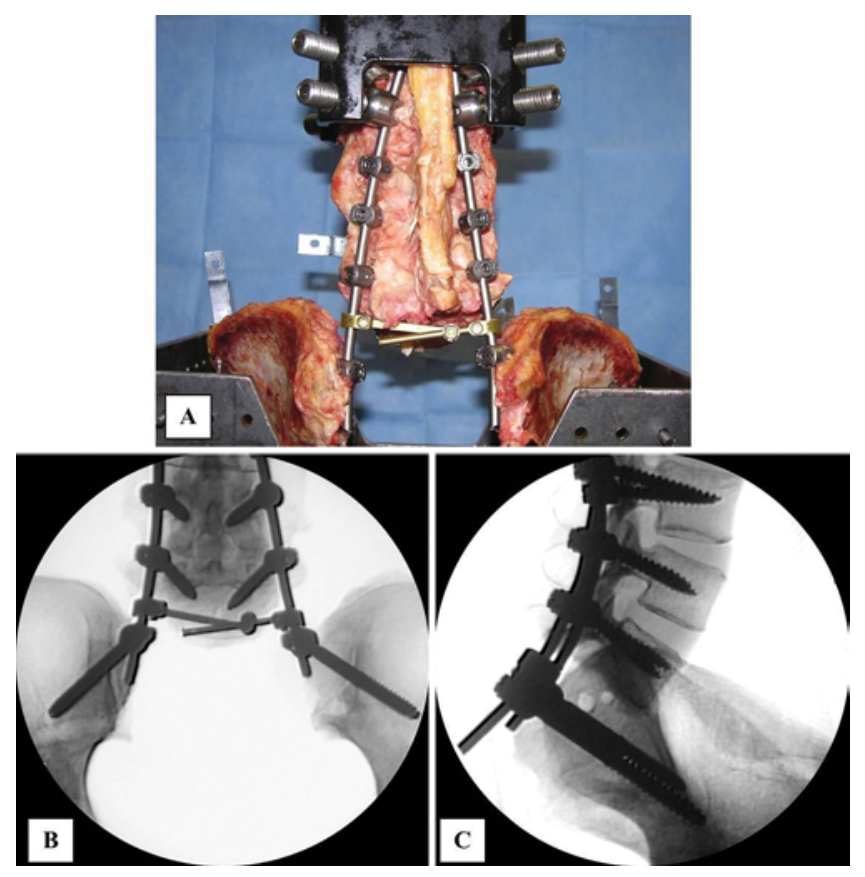

FIG. 2. Model 1. Representative posterior view of the reconstruction procedure using bilateral iliac screws (1 per ilium) attached to pedicle screw-rod instrumentation from L-3 to L-5 (A). Representative anteroposterior (B) and lateral (C) fluoroscopic images are shown demonstrating purchase locations of the transpedicular and iliac screws. Note that the bilateral posterior rods are secured using compression screws on the superior fixation container. Figure is available in color online only.

implanted iliac screws. Using a compression-distraction instrument and 2 rod connectors, the iliac wings were compressed along the bar and secured using rod connectors on the lateral aspects of the implanted bar. This reconstruction method (Model 2, Fig. 3) was biomechanically evaluated using the loads previously applied to the intact spine condition.

\section{Model 3}

Following biomechanical testing of Model 2, the transiliac rod was removed. The inferior iliac screw tunnels were tapped, followed by implantation of $10-\times 100-\mathrm{mm}$ iliac screws to a depth such that the polyaxial screw heads permitted attachment to the medial rods. Two additional bilateral rods (5.5-mm, titanium) were then contoured as needed and implanted medial to the existing rods, and attached using rod connectors at the L3-4, L4-5, and L5proximal iliac screw junctions. The medial rods were secured to the inferior iliac screws and the entire assembly was tightened according to the manufacturer's guidelines. The rods extended superior to L-3, which permitted the compression screws of the superior fixation container to be tightened directly against the rods. This ensured that the load application was directed through the instrumentation and not the proximal uninstrumented level. A crosslink was implanted between the medial rods and located between the superior and inferior iliac screws. The LED OptoTrak marker originally attached to $\mathrm{S}-1$ was reattached to the cross-link. This reconstruction method (Model 3, Fig. 4) was biomechanically evaluated using the loads previously applied to the intact spine condition. 


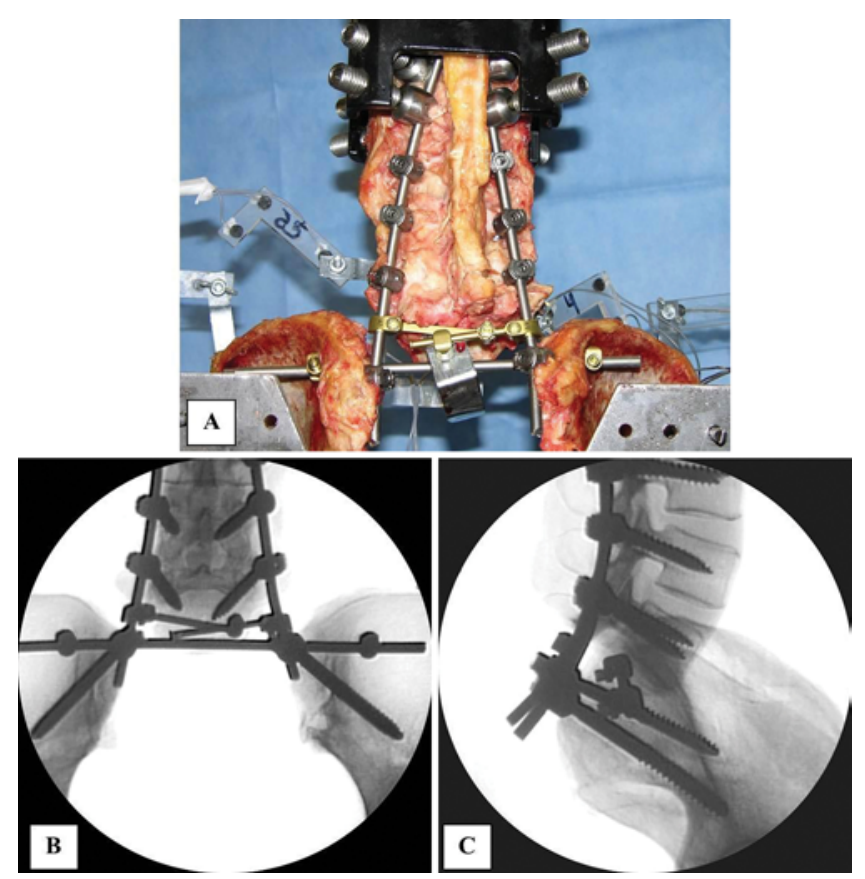

FIG. 3. Model 2. Representative posterior view of the reconstruction procedure using bilateral iliac screws (1 per ilium) attached to pedicle screw-rod instrumentation from L-3 to L-5, and iliac crossbar (A). Representative anteroposterior (B) and lateral (C) fluoroscopic images are shown demonstrating purchase locations of the transpedicular screws, iliac screws, and crossbar. Note that the bilateral posterior rods are secured using compression screws on the superior fixation container. Figure is available in color online only.

In summation, following analysis and biomechanical testing of the intact spine, each of the lumbopelvic specimens underwent a complete sacrectomy and reconstruction according to the following testing sequence: 1) intact spine; 2) sacrectomy (no testing); 3) reconstruction Model $1 ; 4)$ reconstruction Model 2; and 5) reconstruction Model 3 (Figs. 2-4). A total of 8 lumbosacral spines underwent biomechanical testing in this investigation, with the 3D range of motion (ROM), axial, and anteroposterior translation load-displacement properties assessed for the intact spine and 3 reconstruction groups.

\section{Data and Statistical Analysis}

For the 6 main motions-corresponding to the moments applied-the operative-level segmental ROM was calculated as the sum of the neutral zone (NZ) and elastic zone (EZ) (i.e., $\mathrm{NZ}+\mathrm{EZ}=\mathrm{ROM}$ ), and represented the peak total ROM (Euler angles rotation) at the third loading cycle. The expressed degrees rotation (NZ and ROM) (flexion-extension $\pm \mathrm{x}$-axis, lateral bending $\pm \mathrm{z}$-axis, and axial rotation \pm y-axis) for multidirectional flexibility analysis is according to the 3D conceptual framework of White and Panjabi. ${ }^{19}$ For the intact condition, L4-5, L5S1, L5-left ilium, and L5-right ilium rotational motions were quantified. Following reconstruction, the L5-S1 motion was replaced with the L5-instrumentation construct (L5-cross-link) motion. The anteroposterior shear ( \pm $\mathrm{z}$-axis) and axial compression ( $\pm \mathrm{y}$-axis) translations (in millimeters) of L4-5, L5-S1 (or L5-cross-link), L5-left

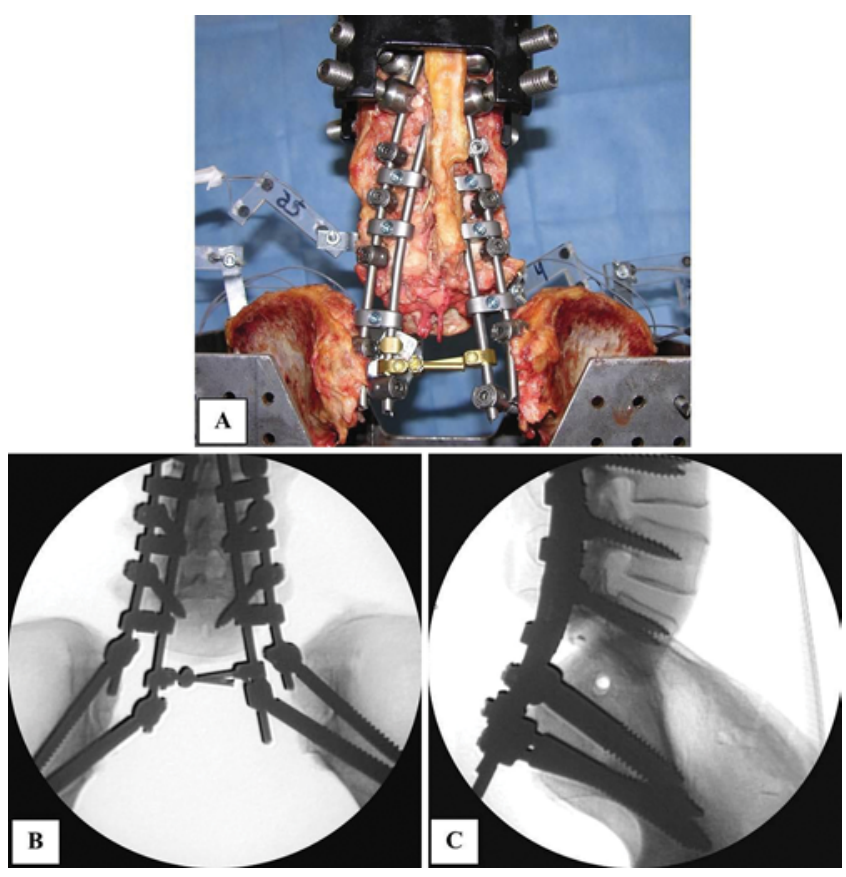

FIG. 4. Model 3. Representative posterior view of the reconstruction procedure using bilateral iliac screws (2 per ilium) attached to pedicle screw-4-rod instrumentation from L-3 to L-5 (A). Representative anteroposterior (B) and lateral (C) fluoroscopic images are shown demonstrating purchase locations of the transpedicular and iliac screws. Note that the bilateral posterior rods are secured using compression screws on the superior fixation container. Figure is available in color online only.

ilium, and L5-right ilium were compared between the 3 reconstructions and the intact spine. As a final test, the L5-pelvis (lumbopelvic) segmental ROM data were correlated with specimen BMD (in grams/cubic centimeters) data by using linear regression analysis and Pearson's $\mathrm{r}^{2}$ test. All data are expressed in absolute values (in degrees and millimeters). Descriptive statistics are expressed as the mean $\pm \mathrm{SD}$. All numerical comparisons were performed with 1-way ANOVA among all 4 cohorts: intact spine, Model 1, Model 2, and Model 3. Statistical significance was set at $\mathrm{p}<0.05$.

\section{Results}

\section{Specimen Reconstruction Procedures}

A total of 8 fresh-frozen human lumbar specimens (L2-pelvis) with an average donor age of 71.6 years (range 53-88 years) were harvested en bloc and used in this investigation. The mean BMD of the specimens was 0.908 $\pm 0.181 \mathrm{~g} / \mathrm{cm}^{3}$ (range $0.623-1.128 \mathrm{~g} / \mathrm{cm}^{3}$ ) (Table 1). Linear regression and correlation analysis were used to compare lumbar vertebral body BMD and range of segmental motion between L-5 and the pelvis. Linear regression analysis of BMD versus L5-ilium segmental ROM did not indicate a significant correlation for any condition, reconstruction, or loading mode. All 8 sacrectomy procedures and subsequent lumbopelvic reconstructions were successfully performed. There were no cases of pedicle wall violation or ilium disruption. 
TABLE 1. Demographic data for 8 human cadaveric specimens

\begin{tabular}{cccc}
\hline Specimen No. & Sex & Age $(\mathrm{yrs})$ & $\mathrm{BMD}\left(\mathrm{g} / \mathrm{cm}^{3}\right)$ \\
\hline 1 & $\mathrm{~F}$ & 53 & 0.694 \\
\hline 2 & $\mathrm{M}$ & 61 & 1.06 \\
\hline 3 & $\mathrm{M}$ & 71 & 0.837 \\
\hline 4 & $\mathrm{~F}$ & 76 & 0.925 \\
\hline 5 & $\mathrm{M}$ & 88 & 1.062 \\
\hline 6 & $\mathrm{M}$ & 74 & 1.128 \\
\hline 7 & $\mathrm{M}$ & 65 & 0.931 \\
\hline 8 & $\mathrm{M}$ & 85 & 0.623 \\
\hline Mean & & 71.6 & 0.908 \\
\hline SD & & 11.8 & 0.181 \\
\hline
\end{tabular}

\section{Flexion-Extension ( $\pm \mathrm{x}$-axis)}

Under flexion-extension loading, the mean flexion-extension ROMs at L4 -5 in Model $1\left(1.54^{\circ} \pm 0.94^{\circ}\right)$, Model $2\left(1.51^{\circ} \pm 1.01^{\circ}\right)$, and Model $3\left(0.72^{\circ} \pm 0.62^{\circ}\right)$ were significantly lower than the intact condition $\left(6.34^{\circ} \pm 2.57^{\circ}\right)(\mathrm{p}<$ 0.001 ) (Table 2). Furthermore, compared with the intact condition $\left(5.56^{\circ} \pm 3.28^{\circ}\right)$, ROM at the L5-right ilium significantly increased in Model $1\left(7.93^{\circ} \pm 2.77^{\circ}\right)$ and Model $2\left(7.03^{\circ} \pm 2.88^{\circ}\right)$, but significantly decreased in Model 3 $\left(2.95^{\circ} \pm 1.27^{\circ}\right)(p=0.005)$. Similar differences were observed at the L5-left ilium ( $\mathrm{p}=0.012)$, indicating that the stability at the L5-iliac communication decreases in Models 1 and 2 and increases in Model 3.

\section{Lateral Bending ( \pm z-axis)}

All 3 reconstruction groups (Models 1, 2, and 3) significantly decreased, statistically, lateral bending ROM compared with the intact condition at all measured points: L4-5 (intact, $\left.6.68^{\circ} \pm 3.81^{\circ}\right)(\mathrm{p}<0.001)$, L5-S1/cross-link (intact, $\left.4.62^{\circ} \pm 2.37^{\circ}\right)(\mathrm{p}<0.001)$, L5-right ilium (intact, $\left.4.95^{\circ} \pm 2.41^{\circ}\right)(\mathrm{p}<0.001)$, and L5-left ilium (intact, $4.92^{\circ}$ $\left.\pm 2.37^{\circ}\right)(\mathrm{p}<0.001)($ Table 2$)$.

\section{Axial Rotation ( \pm y-axis)}

The axial rotation ROM at L4-5 for Model $1\left(2.01^{\circ}\right.$ $\left.\pm 1.39^{\circ}\right)$, Model $2\left(2.00^{\circ} \pm 1.52^{\circ}\right)$, and Model $3\left(1.15^{\circ} \pm\right.$ $0.80^{\circ}$ ) was significantly lower statistically than the intact condition $\left(5.02^{\circ} \pm 2.9^{\circ}\right)(\mathrm{p}<0.001)$ (Table 2). At the L5$\mathrm{S} 1 /$ cross-link, the axial rotation did not vary significantly between the intact and reconstructed conditions $(\mathrm{p}=$ 0.791). The mean axial rotation at the L5-right ilium was significantly higher for Model $1\left(5.14^{\circ} \pm 2.48^{\circ}\right)$ and Model $2\left(4.95^{\circ} \pm 2.45^{\circ}\right)$ in comparison with the intact condition $\left(2.64^{\circ} \pm 1.36^{\circ}\right)$ and Model $3\left(2.93^{\circ} \pm 1.68^{\circ}\right)(p=0.036)$. Similarly, the mean ROM at the L5-left ilium was significantly higher for Model $1\left(5.19^{\circ} \pm 2.34^{\circ}\right)$ and Model 2 $\left(4.99^{\circ} \pm 2.31^{\circ}\right)$ in comparison with the intact model $\left(2.58^{\circ}\right.$ $\left.\pm 1.43^{\circ}\right)$ and Model $3\left(2.93^{\circ} \pm 1.71^{\circ}\right)(\mathrm{p}=0.022)$.

\section{Axial Compression Testing}

Axial compression testing using an MTS 858 Bionix Test System was performed on all specimens for each treatment, except specimen No. 8, for the Models 1 and 2 reconstructions due to concerns about bone quality at the time of instrumentation. Furthermore, these models had a $\mathrm{BMD}$ of $0.62 \mathrm{~g} / \mathrm{cm}^{3}$, which is considered in the lower range of normal. Statistical comparisons across treatment conditions for axial compression translation $( \pm \mathrm{y})$ and anteroposterior shear $( \pm \mathrm{z})$ at L4-5, L5-S1/cross-link, L5-left ilium, and L5-right ilium were not statistically different among all 4 cohorts: intact specimen and reconstruction Models 1, 2, and 3 ( $\mathrm{p}>0.05$ ) (Table 3$)$.

\section{Discussion}

In aggressive and infiltrative tumors of the sacrum, a total sacrectomy may confer the highest probability of

TABLE 2. Multidirectional flexibility ROM $\left(^{\circ}\right)$ in 8 cadaveric lumbopelvic specimens

\begin{tabular}{|c|c|c|c|c|c|}
\hline ROM & Intact & Model 1 & Model 2 & Model 3 & p Value* \\
\hline \multicolumn{6}{|l|}{ Flexion-extension } \\
\hline L4-5 & $6.34 \pm 2.57$ & $1.54 \pm 0.94$ & $1.51 \pm 1.01$ & $0.72 \pm 0.62$ & $<0.001$ \\
\hline L5-S1/cross-link & $4.71 \pm 2.90$ & $4.06 \pm 1.68$ & $3.56 \pm 1.03$ & $2.22 \pm 0.99$ & 0.066 \\
\hline L5-rt ilium & $5.56 \pm 3.28$ & $7.93 \pm 2.77$ & $7.03 \pm 2.88$ & $2.95 \pm 1.27$ & 0.005 \\
\hline L5-It ilium & $5.48 \pm 3.28$ & $7.77 \pm 3.09$ & $6.83 \pm 3.29$ & $2.87 \pm 1.40$ & 0.012 \\
\hline \multicolumn{6}{|l|}{ Lateral bending } \\
\hline L4-5 & $6.68 \pm 3.81$ & $0.76 \pm 0.57$ & $0.57 \pm 0.31$ & $0.32 \pm 0.38$ & $<0.001$ \\
\hline L5-S1/cross-link & $4.62 \pm 2.37$ & $1.11 \pm 0.67$ & $0.80 \pm 0.46$ & $0.43 \pm 0.31$ & $<0.001$ \\
\hline L5-rt ilium & $4.95 \pm 2.41$ & $2.36 \pm 1.30$ & $2.18 \pm 1.25$ & $1.06 \pm 0.52$ & $<0.001$ \\
\hline L5-It ilium & $4.92 \pm 2.37$ & $2.33 \pm 1.28$ & $2.18 \pm 1.25$ & $1.00 \pm 0.46$ & $<0.001$ \\
\hline \multicolumn{6}{|l|}{ Axial rotation } \\
\hline L4-5 & $5.02 \pm 2.90$ & $2.01 \pm 1.39$ & $2.00 \pm 1.52$ & $1.15 \pm 0.80$ & $<0.001$ \\
\hline L5-S1/cross-link & $2.26 \pm 1.33$ & $2.02 \pm 1.49$ & $2.22 \pm 1.70$ & $1.58 \pm 1.43$ & 0.791 \\
\hline L5-rt ilium & $2.64 \pm 1.36$ & $5.14 \pm 2.48$ & $4.95 \pm 2.45$ & $2.93 \pm 1.68$ & 0.036 \\
\hline L5-It ilium & $2.58 \pm 1.43$ & $5.19 \pm 2.34$ & $4.99 \pm 2.31$ & $2.93 \pm 1.71$ & 0.022 \\
\hline
\end{tabular}

* Calculated from 1-way ANOVA. 
TABLE 3. Axial compression translations $(\mathrm{mm})$ in 8 cadaveric lumbopelvic specimens

\begin{tabular}{|c|c|c|c|c|c|}
\hline Compression & Intact & Model 1 & Model 2 & Model 3 & $p$ Value ${ }^{*}$ \\
\hline \multicolumn{6}{|l|}{ $\pm z$-axis } \\
\hline L4-5 & $0.89 \pm 0.83$ & $0.34 \pm 0.34$ & $0.71 \pm 0.77$ & $0.45 \pm 0.54$ & 0.367 \\
\hline L5-S1/cross-link & $1.17 \pm 0.73$ & $0.28 \pm 0.43$ & $0.82 \pm 1.24$ & $0.54 \pm 0.69$ & 0.203 \\
\hline L5-rt ilium & $0.99 \pm 0.69$ & $1.02 \pm 1.59$ & $1.58 \pm 2.05$ & $0.94 \pm 0.71$ & 0.785 \\
\hline L5-It ilium & $0.94 \pm 0.67$ & $1.20 \pm 0.82$ & $1.48 \pm 2.25$ & $1.12 \pm 1.19$ & 0.892 \\
\hline \multicolumn{6}{|l|}{ $\pm y$-axis } \\
\hline L4-5 & $0.32 \pm 0.26$ & $0.27 \pm 0.38$ & $0.29 \pm 0.42$ & $0.18 \pm 0.15$ & 0.830 \\
\hline L5-S1/cross-link & $0.13 \pm 0.16$ & $0.52 \pm 0.49$ & $0.33 \pm 0.28$ & $0.36 \pm 0.35$ & 0.191 \\
\hline L5-rt ilium & $0.22 \pm 0.15$ & $0.60 \pm 0.41$ & $0.74 \pm 0.53$ & $0.59 \pm 0.49$ & 0.114 \\
\hline L5-It ilium & $0.24 \pm 0.08$ & $0.56 \pm 0.56$ & $0.29 \pm 0.29$ & $0.37 \pm 0.31$ & 0.329 \\
\hline
\end{tabular}

* Calculated from 1-way ANOVA.

en bloc resections with negative margins and, thus, a prolonged disease-free survival. Great strides in lumbopelvic reconstructions have been set in motion since the first description of the total sacrectomy reconstruction technique in 1997, with surgeons seeking to perfect this technique. In 2008, an alternative lumbopelvic fixation method was suggested, in which the pelvic ring was reestablished with a transiliac rod..$^{13}$ The pedicular, segmental fixation incorporated 2 vertical rods on each side of the lumbar spine. The nuances among the different reconstruction techniques have not been definitively established with a biomechanical analysis. ${ }^{10,11,20}$

Using a human cadaveric model, the overall objective of this in vitro investigation was to biomechanically compare the multidirectional flexibility and anteroposterior shear properties at the lumbosacral and lumbopelvic junctions following 3 different reconstruction techniques for total sacrectomy-Models 1,2, and 3. The destabilization and reconstruction procedures were performed using a systematic and reproducible technique to minimize interspecimen variability in terms of the biomechanical results. From a reconstruction standpoint, the primary difference between Models 1 and 2 was the addition of the transiliac fixation bar. Model 3 exhibited the greatest differences in terms of instrumentation, with the addition of 2 medial rods and 2 iliac screws to the existing construct.

Multidirectional flexibility testing in the present study included flexion-extension, lateral bending, and axial rotation. All 3 ROM parameters are equally important in determining the optimal reconstruction technique in the clinical context. ${ }^{2,5}$ A favorable construct most closely resembles the intact lumbopelvic ring, which anatomically confers not only support of the spinal column but also laxity for hip motion..$^{14}$ With that said, Model 3, which incorporated 4 rods and 4 iliac screws, was associated with markedly reduced lumbopelvic segmental motion in all loading modes when compared with the intact spine and Models 1 and $2(p<0.05)$. In flexion-extension and axial rotation at the lumbopelvic junction (L5-right ilium and L5-left ilium), the Model 3 reconstruction afforded greater stability than Models 1 and 2. In lateral bending, all 3 reconstruction groups (Models 1, 2, and 3) were associated with significantly decreased ROM compared with the intact condition at all measured points; however, Model 3 exhibited the greatest kinematic advantage. These results are confirmed with similar experimental studies..$^{15,21,22}$ In a fine-element analysis study, Kawahara et al. compared 3 lumbopelvic reconstruction techniques following a sacrectomy. ${ }^{9}$ In that study, modified Galveston reconstruction (MGR) and triangular frame reconstruction (TFR) models were used, which are analogous to Models 1 and 2 from the present study. Kawahara et al. noted significant stress concentration in the spinal rod in the MGR (equivalent to Model 1) and an above-average yield stress in the transiliac bar in the TFR (equivalent to Model 2). These stress points were attributable to excess motion and compromised stability of the fusion construct.

The secondary objective of the current study was to determine if the 3 lumbopelvic reconstructions demonstrated differences in anteroposterior shear or axial translation. Based on the axial compression analysis, comparisons of segmental translations between the intact condition and the 3 reconstruction conditions did not demonstrate significant differences in anteroposterior shear or axial compression translations. In a biomechanical analysis of 4 reconstruction techniques, Cheng et al. found that the axial compression stiffness was significantly different between the treated specimens and the intact specimens. ${ }^{3}$ These results may differ from the findings in the present study due to our low experimental values (range $0.18 \pm 0.15 \mathrm{~mm}$ to $1.58 \pm 2.05$ $\mathrm{mm})$ and high SDs.

Overall, Model 3 (which includes a total of 4 medial rods and 4 iliac screws) exhibited the greatest biomechanical stability as measured by 1) decreased ROMs in all planes (flexion-extension, lateral bending, and axial rotation) at the L4-5 and the bilateral L5-iliac joints; and 2) decreased lateral bending ROM at L5-S1/cross-link. From a clinical standpoint, this represents the most extensive instrumentation technique. Although intuitively the addition of a transiliac bar in Model 2 should offer greater stability, the present biomechanical analysis showed no significant differences with the additional application. The concept of a transiliac bar was adapted in the original Galveston L-rod reconstruction by Gokaslan et al., who explained "the transverse threaded rod is placed to fix opposing iliac bones to each other and thereby prevent axial rotation of 
the lumboiliac union." ${ }^{\prime}$ However, in the present study, the mean ROM in the axial plane was significantly higher at the bilateral L5-ilium cross-links for Model 1 and Model 2 (addition of transiliac rod) in comparison with the intact model and Model 3. Gokaslan et al. also explained that the transiliac rod is necessary to complete the pelvic ring; however, the aforementioned results in the present study demonstrated that the additional superior and inferior iliac screws bilaterally in Model 3 conferred a statistically significantly stronger stability at the L5-ilium gap compared with the threaded rod. Thus, manipulation of the transiliac bar with further fixation points is unlikely to yield biomechanically meaningful or statistically significant differences in experimental testing and, in turn, surgical practice.

Last, as noted in the Methods section, all 8 lumbopelvic specimens were nondestructively tested under 6 sequential loading conditions, including flexion-extension, lateral bending, and axial rotation. Whereas nondestructive testing may seemingly limit prediction of construct failure, the loading conditions (in 4 different dimensions) replicate the most extreme human stresses in vivo, rather than theoretical destructive forces in vitro that are undoubtedly unsurvivable, practically speaking. The loading conditions have been independently verified as a measure of successful arthrodesis. ${ }^{4,12}$ Nevertheless, the kinematic advantage of additional instrumentation should be tempered with the clinical ramifications of a rigid construct. That is, although lack of motion experimentally decreases the risk of construct failure over time, the impaired movement at the lumbosacral spine, especially with additional hardware, may compromise the patient's comfort and, in turn, quality of life. As with all laboratory studies, extrapolating numerical findings to assess clinical significance represents a potential limitation to our study, but also an opportunity to advance translational research with lumbopelvic reconstruction techniques.

\section{Limitations of the Study}

Although we present biomechanically significant results, this study was limited by the small sample size of 8 human cadaveric specimens. Lack of statistical significance in the axial compression testing, specifically, may be secondary to the low experimental values (range $0.18 \pm$ $0.15 \mathrm{~mm}$ to $1.58 \pm 2.05 \mathrm{~mm}$ ) and high SDs. The results of this study have also been confounded by differences in the BMD. Although the means did approach the lower limits of normal, none of the specimens were osteopenic (i.e., $\mathrm{BMD}<-1 \mathrm{~g} / \mathrm{cm}^{3}$ ). Thus, lumbopelvic (i.e., L5-pelvis) segmental ROM data were correlated with BMD to determine if a positive correlation existed between these 2 variables. Linear regression analysis of BMD versus L5-pelvis segmental ROM did not indicate a significant correlation for any reconstruction condition or loading mode, indicating that variations in the BMD have little to no correlation with the ROM outcomes for these 3 instrumentation methods. Last, because Model 3 did confer a stronger kinematic advantage, the additional instrumentation does present a potential conflict of interest with the study's funding source, DePuy. This was mitigated by blinding the DePuy suppliers not only to the statistical analysis of the experimental findings but also to the data presentation in the manuscript (prior to publication). The long-term implications of such an extensive reconstruction process, nevertheless, need further study in clinical trials.

\section{Conclusions}

The addition of a transiliac bar in Model 2 offered no biomechanical advantage to the bilateral rod-iliac screw configuration. The current biomechanical study demonstrates a definitive kinematic advantage of bilateral rods and iliac screws in the Model 3 reconstruction method versus Models 1 and 2. However, the increased stability of Model 3 must be weighed against the patient's clinically decreased lumbopelvic ROM.

\section{Acknowledgments}

This work was made possible thanks to a grant from DePuy Spine (grant number 90054855).

\section{References}

1. Allen BL Jr, Ferguson RL: The Galveston technique for $\mathrm{L}$ rod instrumentation of the scoliotic spine. Spine (Phila Pa 1976) $7: 276-284,1982$

2. Bederman SS, Shah KN, Hassan JM, Hoang BH, Kiester PD, Bhatia NN: Surgical techniques for spinopelvic reconstruction following total sacrectomy: a systematic review. Eur Spine J 23:305-319, 2014

3. Cheng L, Yu Y, Zhu R, Lv H, Jia Y, Zeng Z, et al: Structural stability of different reconstruction techniques following total sacrectomy: a biomechanical study. Clin Biomech (Bristol, Avon) 26:977-981, 2011

4. Cunningham BW, Lewis SJ, Long J, Dmitriev AE, Linville DA, Bridwell KH: Biomechanical evaluation of lumbosacral reconstruction techniques for spondylolisthesis: an in vitro porcine model. Spine (Phila Pa 1976) 27:2321-2327, 2002

5. Dickey ID, Hugate RR Jr, Fuchs B, Yaszemski MJ, Sim FH: Reconstruction after total sacrectomy: early experience with a new surgical technique. Clin Orthop Relat Res 438:4250,2005

6. Emami A, Deviren V, Berven S, Smith JA, Hu SS, Bradford DS: Outcome and complications of long fusions to the sacrum in adult spine deformity: Luque-Galveston, combined iliac and sacral screws, and sacral fixation. Spine (Phila Pa 1976) 27:776-786, 2002

7. Gokaslan ZL, Romsdahl MM, Kroll SS, Walsh GL, Gillis TA, Wildrick DM, et al: Total sacrectomy and Galveston Lrod reconstruction for malignant neoplasms. Technical note. J Neurosurg 87:781-787, 1997

8. Kanis JA: Diagnosis of osteoporosis and assessment of fracture risk. Lancet 359:1929-1936, 2002

9. Kawahara N, Murakami H, Yoshida A, Sakamoto J, Oda J, Tomita K: Reconstruction after total sacrectomy using a new instrumentation technique: a biomechanical comparison. Spine (Phila Pa 1976) 28:1567-1572, 2003

10. Kelly BP, Shen FH, Schwab JS, Arlet V, Diangelo DJ: Biomechanical testing of a novel four-rod technique for lumbo-pelvic reconstruction. Spine (Phila Pa 1976) 33:E400-E406, 2008

11. Le VH, Heckmann N, Jain N, Wang L, Turner AW, Lee TQ, et al: Biomechanical evaluation of supplemental percutaneous lumbo-sacro-iliac screws for spinopelvic fixation following total sacrectomy. J Spinal Disord Tech 28:E181-E185, 2015

12. Lebwohl NH, Cunningham BW, Dmitriev A, Shimamoto N, Gooch L, Devlin V, et al: Biomechanical comparison of 
lumbosacral fixation techniques in a calf spine model. Spine (Phila Pa 1976) 27:2312-2320, 2002

13. McLoughlin GS, Sciubba DM, Suk I, Witham T, Bydon A, Gokaslan ZL, et al: En bloc total sacrectomy performed in a single stage through a posterior approach. Neurosurgery 63 (1 Suppl 1):ONS115-ONS120, 2008

14. Mindea SA, Chinthakunta S, Moldavsky M, Gudipally M, Khalil S: Biomechanical comparison of spinopelvic reconstruction techniques in the setting of total sacrectomy. Spine (Phila Pa 1976) 37:E1622-E1627, 2012

15. Murakami H, Kawahara N, Tomita K, Sakamoto J, Oda J: Biomechanical evaluation of reconstructed lumbosacral spine after total sacrectomy. J Orthop Sci 7:658-664, 2002

16. Raque GH Jr, Vitaz TW, Shields CB: Treatment of neoplastic diseases of the sacrum. J Surg Oncol 76:301-307, 2001

17. Schildhauer TA, Bellabarba C, Nork SE, Barei DP, Routt ML Jr, Chapman JR: Decompression and lumbopelvic fixation for sacral fracture-dislocations with spino-pelvic dissociation. J Orthop Trauma 20:447-457, 2006

18. Tsuchiya K, Bridwell KH, Kuklo TR, Lenke LG, Baldus C: Minimum 5-year analysis of L5-S1 fusion using sacropelvic fixation (bilateral S1 and iliac screws) for spinal deformity. Spine (Phila Pa 1976) 31:303-308, 2006

19. White AA, Panjabi MM: Clinical Biomechanics of the Spine, ed 2. Philadelphia: Lippincott Williams \& Wilkins, 1990

20. Yu Y, Zhu R, Zeng ZL, Jia YW, Wu ZR, Ren YL, et al: The strain at bone-implant interface determines the effect of spinopelvic reconstruction following total sacrectomy: a strain gauge analysis in various spinopelvic constructs. PLoS One 9:e85298, 2014

21. Zhang HY, Thongtrangan I, Balabhadra RS, Murovic JA, Kim DH: Surgical techniques for total sacrectomy and spinopelvic reconstruction. Neurosurg Focus 15(2):E5, 2003
22. Zhu R, Cheng LM, Yu Y, Zander T, Chen B, Rohlmann A: Comparison of four reconstruction methods after total sacrectomy: a finite element study. Clin Biomech (Bristol, Avon) 27:771-776, 2012

\section{Disclosures}

The authors report the following disclosures (unrelated to this manuscript). Dr. Gokaslan is the recipient of research grants from DePuy Spine, AOSpine North America, Medtronic, Neurosurgery Research and Education Foundation, Integra Life Sciences, and K2M. He receives fellowship support from AOSpine North America. He holds stock in Spinal Kinetics and US Spine. Dr. Cunningham is the recipient of a grant from DePuy Spine.

\section{Author Contributions}

Conception and design: Bydon, Macki, De la Garza-Ramos. Acquisition of data: Macki, De la Garza-Ramos. Analysis and interpretation of data: Macki, De la Garza-Ramos, Murgatroyd, Mullinix, Sun, Cunningham. Drafting the article: Murgatroyd, Mullinix, Sun, Cunningham. Critically revising the article: Murgatroyd, Mullinix, Sun, Cunningham, McCutcheon. Reviewed submitted version of manuscript: Murgatroyd, Mullinix, Sun, Cunningham, McCutcheon. Statistical analysis: McCutcheon. Administrative/technical/material support: Gokaslan. Study supervision: Bydon, Gokaslan.

\section{Correspondence}

Mohamad Bydon, Department of Neurosurgery, Mayo Clinic, 200 First St. SW, Rochester, MN 55905. email: bydon.mohamad@ mayo.edu. 